\title{
Grant Opportunities, DCB
}

National Cancer Institute

\section{Source}

National Cancer Institute. Grant Opportunities, DCB. NCI Thesaurus. Code C18817.

The Division of Cancer Biology (DCB) supports a variety of investig ator-initiated research grants from academic institutions, research institutes, and small businesses. Two major types of grants are Program Announcements and Requests for Applications. (from DCB Grant Opportunities) 